\title{
Epistemic Disagreements: A Solution for Contextualists
}

\author{
Giovanni Mion \\ Department of Humanities and Social Sciences, Istanbul Technical University
}

\begin{abstract}
My paper aims to account for the possibility of disagreements concerning what we know; for clearly, people disagree about what they know. More precisely, my goal is to explain how a contextualist theory of knowledge attributions can explain the existence of disagreement among speakers. My working hypothesis is that genuine epistemic disagreement is possible only under the assumption that the meaning of the word 'knowledge' is governed by contexts that are objective, in the sense that that the content of the word 'knowledge' is fixed for all speakers sharing a common conversational goal. The paper is divided into two sections. In the first section, I explain why current versions of epistemic contextualism cannot account for epistemic disagreement. In the second section, following Christopher Gauker's theory of linguistic communication, I offer my own contextualist solution to the problem of epistemic disagreement.
\end{abstract}

Keywords: epistemic contextualism

\section{The Problem}

Notoriously, many linguistic expressions are context sensitive. For example, demonstratives like 'this' are context sensitive. 'This' refers to different things in different contexts of use. Accordingly, if uttered in different contexts, both sentences 'this is red' and 'this is not red' might be true. Gradable adjectives, such as 'tall', are also context sensitive. For instance the claim that John is tall might be true relative to his friends, but false relative to the average basketball player. Accordingly, if uttered in different contexts, both sentences 'John is tall' and 'John is not tall' might be true. 'Everybody' is context sensitive as well. If I claim in front of my classroom that everybody is present, then my claim might be true even if the Queen of England is not among

Corresponding author's address: Giovanni Mion, Department of Humanities and Social Sciences, Istanbul Technical University, 34469 Maslak, Istanbul, Turkey. Email: gmion22@gmail.com. 
my students. Finally, according to epistemic contextualism, 'knowledge' is context sensitive too. Thus, if uttered in different contexts, both sentences 'John knows that the museum is open' and 'John does not know that the museum is open' might be true. Following David Kaplan's distinction between character and content (see Kaplan 1989), the epistemic contextualist believes that sentences containing 'knowledge' have a fixed character, but they might have different contents, and therefore might express different propositions depending upon the context of use.

Epistemic contextualism comes in different versions depending upon one's favorite linguistic model. In short, for Stewart Cohen $(1986,1999)$, since knowledge implies justification and justification comes in degrees, the context sensitivity of 'knowledge' ought to be understood in terms of the context sensitivity of gradable adjectives, such as 'tall, 'flat', 'bald', 'rich'. In contrast, for David Lewis (1996), since 'knowledge that $p$ ' implies the elimination of all the possibilities in which $\sim p$ is true and 'all' is typically restricted to a particular domain, the context sensitivity of 'knowledge' ought to be understood in terms of the context sensitivity of quantified expressions, for example 'all' or 'every'. Finally, for Keith DeRose (1992), the context sensitivity of 'knowledge' is like the context sensitivity of core indexicals (for example, 'here') or demonstratives (for example, 'this').

Depending upon their linguistic model, different epistemic contextualists postulate different context-shifting mechanisms. For Cohen what changes from one context to another is the threshold for justification that the putative knower's belief must reach in order for his or her belief to count as justified, and, if true, as knowledge. So, for example, in the context of philosophical reflection, for Cohen, I (the putative knower) would not know that I have hands because my belief would not meet the threshold for justification imposed by the skeptic. In contrast, for Lewis, what changes from one context to another is the set of relevant alternatives that the putative knower must be able to eliminate in order to count as knowing the proposition in question. So, according to Lewis, in the context of philosophical reflection, I would not know that I have hands because I would not be able to rule out the alternative that I am a brain in a vat. ${ }^{1}$ Finally, for DeRose (1992), what changes from one context to another is the strength of epistemic position that is required in order for the putative knower to count as knowing the proposition in question. So, according to DeRose, in the context of philosophical reflection, I would not know that I have hands because I would be incapable of tracking the truth of the proposition 'I have hands' all the way up into the sphere of mere logical possibilities. In fact, in a context where skepticism

As Lewis concisely puts it, in the context of philosophical reflection, epistemology robs us of our knowledge (Lewis 1996, 550). 
is under examination, I might rightly believe that I have hands, but I would fail to know it because I would continue to believe that I have hands even if I were a brain in a vat. ${ }^{2}$

In any case, in spite of their differences, all epistemic contextualists believe that speakers (or more precisely, knowledge attributors) impose their epistemic standards on putative knowers. ${ }^{3}$ In addition, they also tend (more or less explicitly) to assume that the meaning of 'knowledge' (or more precisely, its content) is determined by the attributors' mental states (i.e. by the attributor's semantic intentions and beliefs). As Jason Stanley writes, according to the contextualist, "what determines the semantic value of instances of 'knows that $p$ ', relative to a context of use, is some collection of facts about the intentions and beliefs of the conversational participants [knowledge attributors] in that context of use" (Stanley 2005, 23). Accordingly, if following Lewis, we assume that ${ }^{~}$ knowledge that $p^{\top}$ implies the elimination of every [relevant] alternative in which $\sim p$, then "the mysterious distinction between relevant and irrelevant alternatives can be grounded in a psychological distinction between what is salient to a speaker versus what is not salient to a speaker, a distinction already independently required in the study of context-sensitivity" (Stanley 2005, 20). ${ }^{4}$

But if we assume that the content of 'knowledge' is "personally indicated", as DeRose (2009, 133-135) likes to put it, then speakers might not be able to disagree even when they take themselves to contradict each other. In fact, if speakers have different relevant alternatives in mind, then genuine epistemic disputes can be reduced to mere verbal disputes, precisely as Cohen seems to be suggesting in the following passage:

${ }^{2}$ For critical discussions of the different versions of epistemic contextualism, see (Blaauw 2005) and (Schaffer 2005). In the case of DeRose, Schaffer correctly notes that "no linguistically general parameter has been identified [in connection with our ability to track the truth], much less one associated with expressions of which 'know' is an instance. There seems to be no precedent for this form of parameter in the language. It seems a pure invention" (Schaffer 2005, 123). In fact, DeRose's idea that knowledge varies according to the strength of epistemic position and that the context sensitivity of knowledge resembles the context sensitivity of indexicals are wholly unrelated.

3 Granted that some philosophers (Michael Williams, for example) call themselves "contextualists" but hold that knowledge attributions are governed by the context of the putative knower, as opposed to the context of the attributor.

4 It is true that some of Lewis's rules in "Elusive Knowledge" (1996) appear to be independent of the speaker's mental states. But this might be only superficially the case. Take the Rule of Actuality: “...the possibility that actuality obtains is never properly ignored" (Lewis 1996, 554). Actuality is certainly a mind independent feature of reality. But this rule is just a fancy way to say that "only what is true is known" (Lewis 1996, 554), which something that has no particular bearing on epistemic contextualism. In other words, the Rule of Actuality is not a context sensitive rule. 
Compare 'know' with a term like 'flat'. Attributions of flatness can vary in truth value depending on what standards are applied. I may look out my window and claim that New Jersey is hilly whereas a giant may assess New Jersey as flat. Each claim can be correct. There is no contradiction, since the contexts of attribution yields different standards. Surely I would not want to claim that what the giant says is false owing to his distorted perspective, or my claim that the road is flat would be subject to the same assessment by an ant-sized being. All of this is familiar enough. Again it is important to see that neither we nor the giant are constrained to use specific standards. I could adopt the giant's standards and agree with him by truthfully stating that New Jersey is flat (Cohen 1986, 580).

But now consider the following epistemic dispute: John and Mary are planning a trip to Egypt and their travel agent (Mike) informs them that they do not need a visa to visit that country. On their way home, John attempts to reassure Mary and accordingly, he claims: "Mike knows that we do not need a visa to enter Egypt"; but Mary who is thinking about Egypt's current political situation, and consequently, about the possibility of a more restrictive law, replies: "Mike does not know that we do not need a visa for our trip".

In this case, it seems to me that John and Mary (the attributors) have a genuine disagreement concerning Mike's epistemic status, and therefore, that they are contradicting each other. However, if, following current epistemic contextualism, we assume that the content of 'knowledge' is personally indicated, then we should conclude that they are both right (or that their claims are truth-valueless). ${ }^{5}$ In fact, if we assume that during their conversation John and Mary are in different mental states, then we should conclude that they are not using 'knowledge' with the same content, and accordingly, that they do not have a genuine disagreement. So, suppose that Mike is right about the visa, but also that he would not be able to rule out the possibility entertained by Mary. In this case, John's assertion that Mike has knowledge is true. After all, John is not contemplating the possibility of a more restrictive law. But also Mary's assertion that Mike does not have knowledge is true. In fact, Mike would not be able to rule out the possibility of a new more restrictive law.

Now, suppose that during his conversation with Mary, thanks to a series of conversational maneuvers (for which DeRose provides no account), ${ }^{6}$ John succeeds in putting in place his personally indicated content for knowledge. (In other words, suppose that somehow John manages to impose his

5 This last one is the solution that DeRose would seem to favor, see (DeRose 2009, chapter 4).

${ }^{6}$ See (DeRose 2009, 133). 
epistemic standards upon Mary). Now that we have shared epistemic standards (or a single scoreboard semantics, in DeRose's terminology), we can make room for disagreement. But since John's standards are more relaxed than Mary's, we should conclude that John is right and Mary is wrong. But this is a mistake. Since John is neglecting the current political situation in Egypt, we should conclude that Mary is right and John is wrong. But this is a result that DeRose cannot deliver.

I am a contextualist about 'knowledge'. More precisely, like Lewis, I believe that knowledge is a modal notion ${ }^{7}$ that requires a distinction between possibilities that are contextually relevant (relevant alternatives) and possibilities that are contextually irrelevant. In other words, I believe that the meaning of the word 'knowledge', or more precisely its content, is determined by a set of possibilities; that such possibilities vary across conversational contexts; and finally, that a subject $X$ knows that $p$ only if he or she can rule out the possibilities in question in which $\sim p$. However, I do not think that current versions of epistemic contextualism (including Lewis's) can properly handle cases of disagreement.

In "Is There a Good Objection to Contextualism to be Found in its Inability to Handle Cases of Disagreement?" (DeRose 2009, 151-152), DeRose himself acknowledges the problem of disagreement as follows: "presumably, there is some correct solution to these problems-unless you want to deny that there are any context-sensitive terms" (DeRose 2009, 152).

DeRose is right; there is a solution to the problem of disagreement, but his move is merely rhetorical. First, he correctly traces the problem of epistemic disagreement back to disagreement involving other context sensitive terms (see DeRose 2009, 143), ${ }^{8}$ but then instead of tackling it, he brushes it aside. In fact, he seems to believe that since the problem encompasses all context sensitive expressions, it is not an urgent threat to his account of knowledge attributions: "Are there any special problems that arise for contextualism about 'know(s)' in these situations? If not, there does not seem to be much of an objection to epistemic contextualism to be found here" (DeRose 2009, 152). But in this way he leaves a formidable weapon in the hands of the invariantist: ${ }^{9}$ since disagreements about knowledge attributions do not pose any challenge to invariantist accounts of 'knowledge', the invariantist can use these problems to neutralize contextualism.

7 For a discussion of the connections between epistemic contextualism and formal epistemology see (Hendricks 2006). In particular, in chapter five, Hendricks systematically explores the connections between Lewis's epistemic contextualism and modal epistemology.

${ }^{8}$ DeRose uses the term 'here', but 'all' would have been more appropriate.

9 Notoriously, a modal invariantist believes that there exists only one single set of possibilities that governs all knowledge attributions. 
In any case, the right solution does not consist in denying the existence of context sensitive expressions (nobody would do that), nor in denying the context sensitivity of 'knowledge' (as the invariantist would do), but it depends upon a revision of how context sensitive expressions in general acquire their meaning.

\section{The Solution}

Consider the following case involving the context sensitive expression 'all':

Suppose that Suzy is sitting on the floor in her bedroom playing with glass marbles. All of the marbles in Suzy's room belong to Suzy, and some of them are red. Suddenly Tommy comes into Suzy's room and declares in a loud voice, "All of the red ones are mine!" As a matter of fact, when Tommy says this he is thinking of the marbles in his own room. The proposition he is expressing is the proposition that all of the red marbles in his room are his. Tommy is very proud of his possessions and on this occasion is exulting in his possession of red marbles. But there is no way Suzy could know that. She would naturally expect that he was talking about the marbles there on the floor in plain view of both of them. So of course she retorts, "No they're not!" (Gauker 2003, 78).

Is Suzy right or wrong? If you believe that the content of 'all' is relative to what Suzy has in mind when she claims 'No, they're not!', then you would conclude that she is right. After all, she has in mind the marbles on the floor, and the marbles on the floor belong to her. But for the same reasons, you should conclude that Tommy is also right. After all, he has in mind the marbles in his room, and the marbles in his room belong to him. Alternatively, if you believe that the primary function of linguistic communication is to become acquainted with other people's mental states, then you should conclude that Tommy is right and Suzy is wrong. After all, Suzy fails to recognize what Tommy has in mind. Given the presence of red marbles on the floor, she might be excused for her failure to read Tommy's mental state. But, from the fact that her assertion might have been justified, we should not infer that it was also true.

In any case, this is all wrong. In fact, there is a distinction between what Tommy means and what he actually says given the context in which he speaks. But once we consider the actual context in which the conversation takes place, we are bound to acknowledge that since Tommy, in contrast to Suzy, disregards what is objectively relevant in light of their surroundings, he is the one who is mistaken, and not Suzy. In other words, since Tommy is wrong about the context that truly pertains to his conversation with Suzy, he might very well be aware of what he means, but he is not aware of what he says. 
According to Gauker (2003), philosophers are generally mistaken about Tommy and Suzy. In fact, since they wrongly tend to assume that the main purpose of linguistic communication is to share thoughts, they also believe that meanings are "in the head". ${ }^{10}$ However, if in contrast to them, we assume that the main purpose of linguistic communication is not to share thoughts, but to achieve practical goals, ${ }^{11}$ and accordingly, that the content of context sensitive expressions depends upon the best way to achieve the goals of the conversation, then we can better account for a wide variety of linguistic phenomena, including, as we shall presently see, epistemic disagreements. ${ }^{12}$

If the context that governs a conversation depends upon how the world really is, relative to a conversational goal, then since speakers might be mistaken about the world, it follows that speakers might be also mistaken about the context that truly governs their conversation. Accordingly, we can draw a distinction between the context that truly pertains to a conversation (the $o b$ jective context), ${ }^{13}$ and what each speaker takes to be the context that pertains to his or her conversation. This implies that, depending upon their conversational goals, different conversations are governed by different objective contexts, and that for each conversation, there exists a specific objective context that governs it and that speakers might fail to grasp. Ultimately, it is the objective context that allows for the possibility of disagreement (and as long as speakers share similar goals, they do not even have to take part to the same conversation in order to be in disagreement). In fact, even if all speakers are mistaken about the context that truly governs their conversation, what they actually say depends upon it.

It could be objected that since the goals of the conversation are determined by the speakers' desires, the content of 'knowledge' must ultimately depend upon the speakers' mental states. But this would be a mistake: from

${ }^{10}$ This is reminiscent of semantic externalism, but for reasons that I cannot properly address in this paper, in Words Without Meaning, Gauker prefers to "abandon all theoretical use of the concept of content" (Gauker 2003, 283), and therefore meaning.

${ }^{11}$ To clarify, I do not intend to deny a role for the notion of 'understanding'. In a sense, understanding is prior to action. In fact, in order to use language to achieve practical goals, people must be able to understand each other. In other words, in order to act upon somebody else's assertion, a person needs to understand the assertion in question. But this does not contradict the claim that the primary function of language is to achieve practical goals. Sometimes, when the conversational goal in question is purely intellectual, we speak just to share our thoughts. But when the conversational goal in question is practical, then we speak to achieve the conversational goal and not just to share our thoughts.

${ }^{12}$ In Words Without Meaning (2003), Gauker successfully applies his contextualist semantics to a wide variety of linguistic phenomena, including demonstratives, conditionals, quantifiers and belief attributions.

${ }^{13}$ Following Gauker (2003), I will assume that objective contexts are theoretical entities like models in formal logic. 
the fact that the speakers' goals depend upon their desires, we should not infer that the content of the word they use is determined by their mental states, as opposed to the best way to achieve their conversational goals. So, if we assume that Tommy and Suzy share a common conversational goal (establish the owner of the marbles) and accordingly, that their conversation is governed by an objective context, then even if Suzy is thinking about her marbles and Tommy about his marbles, they are using the word 'all' intersubjectively (in the sense that what they are saying may be evaluated in light of objective features of the situation in which they speak). In fact, if throughout their conversation, the content of the word 'all' remains fixed by the marbles in their surroundings, we can make room for disagreement between the two. Likewise, if we assume that John and Mary in my previous example share a common conversational goal (establish Mike's epistemic status for the purpose of their trip) and accordingly, that their conversation is governed by an objective context, we can account for their disagreement as well.

In a conversational context where the ultimate goal is to enter Egypt, John and Mary must, among other things, establish the epistemic status of their travel agent (Mike) for the purpose of their trip. But in order to properly evaluate Mike's epistemic status, they need to take into account the current political situation in Egypt. Given the recent events, it is fair to assume that the objective context that governs their conversation does contain the possibility that due to a new law, they might require a visa to enter the country. In other words, in their conversational context, this possibility is a relevant alternative. Accordingly, Mike knows that they do not require a visa only if he can rule it out. Now, suppose that Mike is right, in the sense that they do not require a visa, but that he would not be able to rule out the possibility of a new more restrictive law. In this case, John is wrong and Mary is right. As we saw, John, in contrast to Mary, is not taking into account the possibility in question, but since that possibility belongs to the context that governs his conversation with Mary, it contributes to determining the content of the word 'knowledge' as used by both Mary and John throughout their conversation.

So although John and Mary share the same conversational goals, and accordingly, their use of 'knowledge' is governed by same context, John's take on the objective context that governs his conversation with Mary is deficient. John (like Mary) knows that he is trying to establish Mike's epistemic status for the purpose of a trip to Egypt, but since (unlike Mary) he neglects Egypt's current political situation, he does not know which possibilities Mike must be able to rule out in order to have knowledge. Accordingly, he attributes to Mike the wrong epistemic status. 
So, if we consider the possibility that context sensitive expressions, including 'knowledge', owe their semantic value to non-mental facts, then we can easily account for disagreement within the boundaries of a contextualist epistemology. In fact, if the content of the word 'knowledge' is governed by objective contexts, then speakers can disagree about what people know. In other words, if the content of the word 'knowledge' is fixed for all speakers sharing a common conversational goal, then sentences of the form ' $X$ knows that $p^{\urcorner}$and ${ }^{\top} X$ does not know that $p^{\urcorner}$turn out to be contradictory.

\section{Bibliography}

Blaauw, M. (2005). Introduction: Epistemological contextualism, Grazer Philosophische Studien 69: i-xvi.

Cohen, S. (1986). Knowledge and context, Journal of Philosophy 83: 574-583.

Cohen, S. (1999). Contextualism, skepticism, and the structure of reason, in J. Tomberlin (ed.), Epistemology, Vol. 13 of Philosophical Perspectives, Oxford University Press, Oxford, pp. 57-90.

DeRose, K. (1992). Contextualism and knowledge attributions, Philosophy and Phenomenological Research 52: 913-929.

DeRose, K. (2009). The Case for Contextualism: Knowledge, Skepticism, and Context, Vol. 1, Oxford University Press, Oxford.

Gauker, C. (2003). Words without Meaning, MIT Press, Cambridge, MA.

Hendricks, V. (2006). Mainstream and Formal Epistemology, Cambridge University Press, Cambridge.

Kaplan, D. (1989). Demonstratives, in J. Almog, J. Perry and H. Wettstein (eds), Themes from Kaplan, Oxford University Press, Oxford, pp. 481-564.

Lewis, D. (1996). Elusive knowledge, Australasian Journal of Philosophy 74: 549-567.

Schaffer, J. (2005). What shifts? Thresholds, standards, or alternatives?, in P. Preyer (ed.), Contextualism in Philosophy. Knowledge, Meaning, and Truth, Oxford University Press, Oxford, pp. 115-130.

Stanley, J. (2005). Knowledge and Practical Interests, Oxford University Press, Oxford. 